\title{
Clinical and Ultrasound Concordance of Joint Damages in Rheumatoid Arthritis in a Resource-Limited Country
}

\author{
Sonia B. M. G. Adjadohoun', Miralda Kiki², Maurice M. W. D. Akanni², Boris Vidégla1, \\ Perpétue Batcho ${ }^{3}$, Kofi-Mensa S. Savi de Tovè ${ }^{2}$, Patricia Yèkpè Ahouansou1, \\ Zavier C. Zomalheto ${ }^{3}$, Olivier Biaou'1, Vicentia Boco ${ }^{1}$

\begin{abstract}
${ }^{1}$ Medical Imaging Department, Faculty of Health Sciences, University of Abomey Calavi, Cotonou, Republic of Benin
${ }^{2}$ Regional and Teaching Hospital of Borgou/Medical Imaging Department, Faculty of Medicine, University of Parakou, Parakou, Republic of Benin

${ }^{3}$ Rheumatology Department, Faculty of Health Sciences, University of Abomey Calavi, Cotonou, Republic of Benin

Email: mahussi222@yahoo.fr
\end{abstract}

How to cite this paper: Adjadohoun S.B.M.G., Kiki, M., Akanni, M.M.W.D., Vidégla, B., Batcho, P., de Tovè, K.-M.S.S., Ahouansou, P.Y., Zomalheto, Z.C., Biaou, O. and Boco, V. (2021) Clinical and Ultrasound Concordance of Joint Damages in Rheumatoid Arthritis in a Resource-Limited Country. Open Journal of Radiology, 11, 126-137.

https://doi.org/10.4236/ojrad.2021.113012

Received: August 21, 2021

Accepted: September 24, 2021

Published: September 27, 2021

Copyright (c) 2021 by author(s) and Scientific Research Publishing Inc. This work is licensed under the Creative Commons Attribution International License (CC BY 4.0).

http://creativecommons.org/licenses/by/4.0/

\begin{abstract}
Introduction: Rheumatoid arthritis (RA) is the most common chronic inflammatory rheumatism. The increasing use of bone and joint ultrasound as a tool to aid in the detection of unrefined synovitis in developed countries, has led us to study the performance of ultrasound in the diagnosis of RA in subjects consulting in rheumatology at Cotonou. Study Method: Descriptive cross-sectional study of patients with RA, selected on the basis of ACR/ EULAR 2010 criteria. A complete clinical examination with imaging including X-rays and ultrasounds of the hands and feet were performed in all patients who have given their consent. The data collected was analyzed using EPI data 3.1 and SPSS 24.0 software. The significance rate was defined with a p-value $<5 \%$. Cohen's Kappa $(\mathrm{k})$ test was used to assess agreement. Results: All 53 patients included had lesions on ultrasound. Synovitis was found in 98.1\% and bone erosions in $88.7 \%$. There was no agreement in the wrists between clinical examination and ultrasound $(\mathrm{k}=-0.116)$, MCP $(\mathrm{k}=-0.097)$ and MTP $(k=-0.031)$. Agreement was very low at the PPI level $(k=0.03)$. It was low at the different sites, between ultrasound and radiographic detection of lesions ( $k$ between $0.022-0.22$ ). Age, positive immunologic RA factor and biological inflammatory syndrome were associated with ultrasound erosions $(\mathrm{p}=0.0001)$ and only age was associated with active synovitis $(\mathrm{p}=0.022)$. Conclusion: Bone and articular ultrasound is a good complementary alternative to clinical examination and radiography diagnostic in early diagnosis of RA in our developing countries, in the absence of MRI which remains a luxury.
\end{abstract}




\section{Keywords}

Rheumatoid Arthritis, Ultrasound, Erosions, Synovitis, Cotonou

\section{Introduction}

Rheumatoid arthritis (RA) is an immune-mediated chronic inflammatory joint disease in which synovial proliferation, pannus formation and bone erosions are histologic lesions [1]. It affects around $1 \%$ of the adult population of all sexes [2]. In Benin, its frequency is $0.8 \%$ [3] [4]. The European League Against Rheumatism (EULAR) and the American College of Rheumatology (ACR) in 2010 established criteria for the early diagnosis of RA. These criteria are essentially based on clinical and biology, eliminating often late radiographic criteria [1].

In recent years, modern imaging including Magnetic Resonance Imaging (MRI) and ultrasound have proven to be more sensitive than standard X-rays for early detection of synovitis and bone erosions for the early diagnosis of RA [5]. Ultrasound has become increasingly important in the early diagnosis and monitoring under treatment of RA [6] given its accessibility, its non-irradiating nature, its multi-site explorability and the reasonable cost compared to MRI. Osteoarticular ultrasound, increasingly practiced by specialists (radiologists and rheumatologists) therefore appears to be a good diagnostic alternative complementary to clinical examination in developing countries. The reinforcement of the medical staff by specialists in osteoarticular imaging at the Benin referral hospital made it possible to carry out this work. Our objective was to assess the clinical and ultrasound concordance of joint lesions in rheumatoid arthritis at the National University Hospital Center-Hubert Koutoukou Maga (CNHU-HKM) Cotonou in the Republic of Benin.

\section{Patients and Methods}

This was a descriptive and analytical cross-sectional study carried out from October to December 2018 in the medical imaging and rheumatology departments of the CNHU-HKM in Cotonou.

This was a convenience sampling by an exhaustive census of patients followed in the rheumatology department meeting the following criteria:

- To be followed for at least 6 months.

- Have a diagnosis of RA selected on the basis of EULAR ACR 2010 criteria.

- Have performed an ultrasound of the wrists, hands and feet.

- Have given informed consent.

Patients with another rheumatic pathology associated with RA or in whom ultrasound could not be performed because of joint deformities were excluded.

All the patients underwent a clinical osteoarticular examination carried out by a rheumatologist during which he tried as possible to collect socio-demographic (age, sex), clinical and biological data and the DAS 28 activity score (Disease Ac- 
tivity Score Index 28) of the disease. Each patient received after that, frontal $\mathrm{X}$-rays of both hands taking the wrists and both forefoots, then an osteoarticular ultrasound of the 32 articulated joints (the 2 wrists, the 10 MCP and PPI of the hands and the $10 \mathrm{MTP}$ ). The ultrasound was performed according to the daily practice protocol proposed by Guerini [7].

In addition, the $\mathrm{X}$-rays were interpreted and the ultrasounds carried out by two (02) radiologists and when discrepancy, the opinion of the most experienced was retained. X-rays and ultrasound were subsidized by the hospital.

The clinical, radiological and ultrasound diagnostic criteria for lesions observed in RA have been summarized in Table 1 [8].

The data entry was carried out with Epi data 3.1 French version software. SPSS version 24.0 software enabled data analysis with a significance level " $<5 \%$ " defined for a p-value.

Quantitative variables were described by the mean with the standard deviation (normal distribution) or the median followed by extremes. Cohen's non-parametric Kappa (k) test was used to estimate the rate of concordance or concordance between the results obtained on ultrasound and in the clinic, on the one hand, then between the results of the ultrasound and those of radiography on the other hand. The Landis and Koch classification was used to qualitatively assess the rate of agreement between observations [9]. The concordance between clinical and ultrasound was assessed using "synovitis" which is the characteristic lesion of RA. The concordance between the X-ray and the ultrasound was assessed on bone erosions. The observations were judged to be concordant when the Kappa coefficient was statistically different from 0 . The concordance was either very weak $(\mathrm{k}=0-0.20)$, weak $(\mathrm{k}=0.21-0.40)$, moderate $(\mathrm{k}=0.41-0.60)$, strong $(\mathrm{k}$ $=0.61-0.80)$ or nearly perfect $(\mathrm{k}=0.81-1)$.

Table 1. Diagnostic criteria for rheumatoid arthritis lesions at clinic, radiography and ultrasound [8].

\begin{tabular}{|c|c|c|c|}
\hline & Clinical & Radiography & Ultrasound \\
\hline Synovitis & $\begin{array}{l}\text { Swelling of the } \\
\text { peri-articular soft parts }\end{array}$ & $\begin{array}{l}\text { Increased local density and erasure of } \\
\text { some greasy lines }\end{array}$ & $\begin{array}{l}\text { Hypoechogenic synovial thickening, poorly compressible } \\
\text { and vascularized in doppler power. The power Doppler } \\
\text { allows to grade the increasing activity of this synovitis in } \\
\text { stage } 1,2 \text { and } 3 \text {. In case of hypoechogenic synovial } \\
\text { thickening without doppler flow, the term inactive } \\
\text { synovitis in doppler power is preferred }\end{array}$ \\
\hline Erosion & - & $\begin{array}{l}\text { Rupture of the bony cortical leaving in } \\
\text { place a gap }\end{array}$ & Net irregularity or interruption of the cortical \\
\hline Tenosynovitis & $\begin{array}{l}\text { Inflammatory involvement } \\
\text { of the synovial sheaths of } \\
\text { the tendons }\end{array}$ & $\begin{array}{l}\text { Increased local density and erasure of } \\
\text { some greasy lines }\end{array}$ & $\begin{array}{l}\text { Liquid effusion, anechogenic within a tendon sheath, } \\
\text { hypoechogenic synovial proliferation or a combination of } \\
\text { both }\end{array}$ \\
\hline Joint pinching & - & Overall thinning of articular cartilage & Overall thinning of articular cartilage \\
\hline Joint deformation & $\begin{array}{l}\text { Disorganization of joint } \\
\text { structure }\end{array}$ & $\begin{array}{l}\text { Disorganization of joint } \\
\text { structure }\end{array}$ & Disorganization of joint structure \\
\hline $\begin{array}{l}\text { Demineralization } \\
\text { in strips }\end{array}$ & - & $\begin{array}{l}\text { Density anomaly characterized by a } \\
\text { disparition of at least } 30 \% \text { of the calcium } \\
\text { contained in the bone and translated by } \\
\text { a radio-transparency. }\end{array}$ & \\
\hline
\end{tabular}




\section{Results}

A total of fifty-three (53) female subjects are eligible to the study's criteria inclusion within a total of $102 \mathrm{RA}$ patients collected during the period. The average age was $55 \pm 13$ years with extremes of 11 and 58 years.

\subsection{Clinical and Biological Manifestations}

A family history of RA was found in 21 (39.6\%) patients. The mean age of patients at onset was $41.5 \pm 13.9$ years.

Clinical and biological characteristics of the participants are summarized in Table 2.

The joint most frequently affected by synovitis in the patients was the metacarpo-phalangeal with a frequency of $79.2 \%$. Figure 1 shows the distribution of patients according to the joints involved in RA.

Table 2. Clinical and biological manifestations.

\begin{tabular}{ccc}
\hline & Staff & Percentage (\%) \\
\hline Clinical articular manifestations & 53 & 100 \\
Synovitis & 37 & 69.8 \\
Joint stiffness & 25 & 77.4 \\
Joint deformation & 9 & 17 \\
Extra articular manifestations & 25 & 47.05 \\
Rheumatoid nodule & 14 & 26.4 \\
Vasculitis & 2 & 3.8 \\
Pneumonia & 3 & 5.7 \\
Lymphadenopathy & 3 & 5.7 \\
Adenopathy & 3 & 5.7 \\
Biological inflammatory syndrome & 37 & 69.8 \\
RA factor was seropositive & 32 & 60.4 \\
Remission & & 25.5 \\
High disease activity & & 3.9 \\
\hline
\end{tabular}

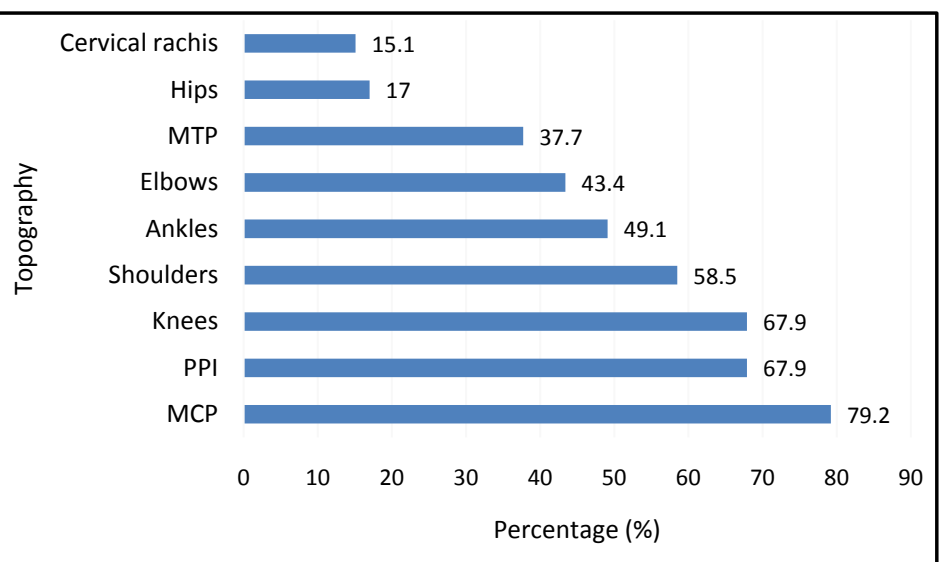

Figure 1. Distribution of patients according to joints affected during RA, Rheumatology Department of CNHU-HKM in 2018 ( $\mathrm{N}=53)$. 


\subsection{Radiographic Lesions}

46 of the 53 patients who were investigated $(86.8 \%)$ presented lesions on the $\mathrm{X}$-ray. Bone erosion was the most common radiographic lesion in 43 of them, $81.1 \%$ (Table 3). These bone erosions were bilateral in 39 (90.7\%) patients.

\subsection{Ultrasound Lesions}

The ultrasound revealed lesions in all patients, unlike the X-ray. Ten types of lesions were observed; the most frequent were synovitis in 52 patients (98.1\%) and bone erosions in $47(88.7 \%)$ cases (Table 4$)$.

Inactive synovitis (Figure 2) was more frequently observed in metatarsophalangeal and metacarpophalangeal with the same prevalence of $94.2 \%$ at these two sites.

\subsection{Clinico-Ultrasound Concordance}

Table 5 summarizes the clinical and ultrasound concordance of synovitis in the different groups of joints. Active synovitis (Figure 3) was observed in $20.8 \%$ of patients at the clinic and in $17 \%$ of patients on ultrasound.

Table 3. Main radiographic lesions in patients followed for rheumatoid arthritis, Rheumatology Department of the CNHU-HKM in $2018(\mathrm{~N}=53)$.

\begin{tabular}{ccc}
\hline & Staff & Percentage (\%) \\
\hline Bone erosions & $\mathbf{4 3}$ & $\mathbf{8 1 . 1}$ \\
Bone demineralization & 28 & 52.8 \\
Joint pinching & 20 & 37.7 \\
Joint deformation & 16 & 30.2 \\
Swelling of the soft parts & 3 & 5.7 \\
Geodes & 2 & 3.8 \\
\hline
\end{tabular}

Table 4. Main ultrasound lesions in patients followed for rheumatoid arthritis, Rheumatology Department of the CNHU-HKM in 2018 ( $\mathrm{N}=53)$.

\begin{tabular}{ccc}
\hline & Staff & Percentage (\%) \\
\hline Inactive synovitis & 52 & $\mathbf{9 8 . 1}$ \\
Bone erosions & 47 & $\mathbf{8 8 . 7}$ \\
Overlap type deformation & 32 & 60.4 \\
Joint effusion & 18 & 34.0 \\
Active synovitis & 9 & 17.0 \\
Inactive tenosynovitis & 9 & 17.0 \\
De Quervain tendinitis & 4 & 7.5 \\
Angulation type deformation (MCP, MTP) & 4 & 7.5 \\
Active tenosynovitis & 2 & 3.8 \\
Thumb gutter cyst & 1 & 1.9 \\
\hline
\end{tabular}


Table 5. Clinical and ultrasound concordance of synovitis (active or not) in patients followed for RA according to the different groups of joints, Rheumatology department of the CNHU-HKM in $2018(\mathrm{~N}=53)$.

\begin{tabular}{|c|c|c|c|c|c|c|c|}
\hline \multirow{2}{*}{ Clinical } & \multicolumn{4}{|c|}{ Ultrasound } & \multirow{2}{*}{ Total } & \multirow{2}{*}{ Kappa (k) } & \multirow{2}{*}{ Interpretation } \\
\hline & \multicolumn{2}{|c|}{ Synovitis (+) } & \multicolumn{2}{|c|}{ Synovitis } & & & \\
\hline Synovitis (+) & 13 & $(24.5)$ & 24 & $(45.3)$ & $37(69.8)$ & -0.116 & Disagreement \\
\hline Synovitis & 8 & $(15.1)$ & 8 & $(15.1)$ & $16(30.2)$ & & \\
\hline \multicolumn{8}{|l|}{ MCP } \\
\hline Synovitis $(+)$ & 39 & $(73.6)$ & 3 & $(5.7)$ & $42(80.8)$ & -0.097 & Disagreement \\
\hline Synovitis & 10 & $(18.9)$ & 0 & $(0.0)$ & $10(19.2)$ & & \\
\hline \multicolumn{8}{|l|}{ PPI } \\
\hline Synovitis (+) & 28 & $(52.8)$ & 8 & $(15.1)$ & $36(69.2)$ & 0.03 & Very weak agreement \\
\hline Synovitis & 12 & $(22.6)$ & 4 & $(7.5)$ & $16(30.8)$ & & \\
\hline \multicolumn{8}{|l|}{ MTP } \\
\hline Synovitis (+) & 18 & $(34.0)$ & 2 & $(3.8)$ & $20(37.7)$ & -0.031 & Disagreement \\
\hline Synovitis & 31 & $(58.5)$ & 2 & $(3.8)$ & $33(62.3)$ & & \\
\hline
\end{tabular}

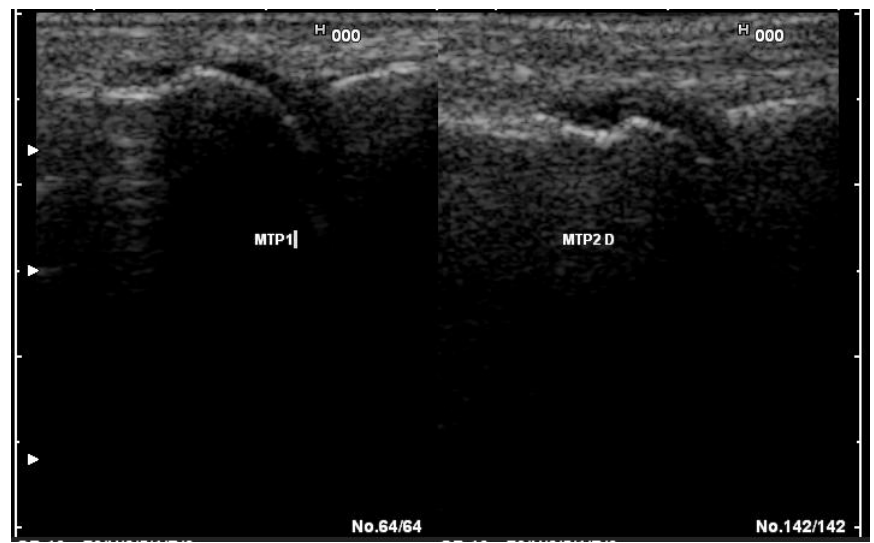

Figure 2. Inactive synovitis of a right MTP1 and inactive synovitis with erosion of a right MTP2 in mode B in a 37-year-old patient followed for RA for 1 year.

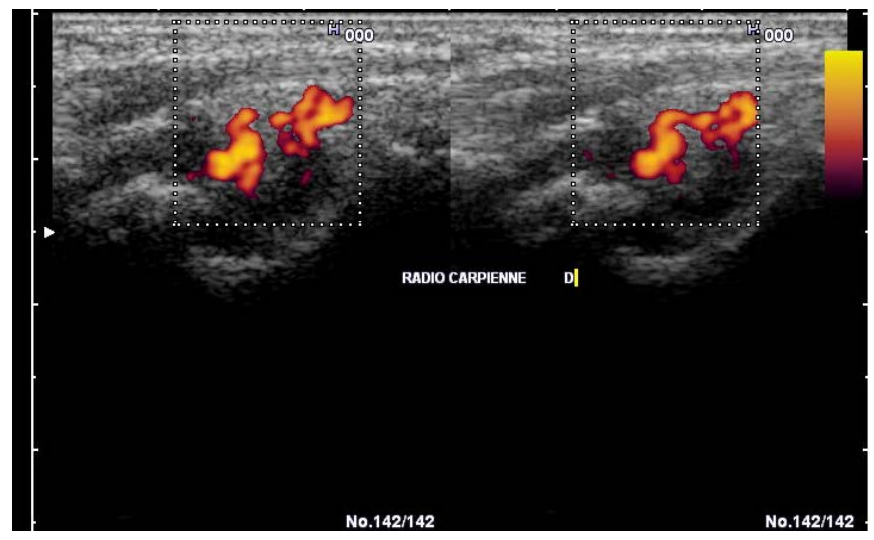

Figure 3. Active grade 2 synovitis of a right radiocarpal joint in B-mode with power doppler in a 40 -year-old patient followed for RA for 2 years. 
Concordance between clinic and ultrasound (Table 6) regarding the diagnosis of active synovitis was very low $(\mathrm{k}=0.16)$.

\subsubsection{Comparison between Radiography and Ultrasound}

This comparison was made on the basis of the presence of bone erosions in the distal joints affected by RA (wrist, MCP, PPI, MTP) (Table 7). There is a weak concordance between ultrasound erosions and radiographic erosions ( $\mathrm{k}$ between 0.022 and 0.22 ). Nevertheless, the ultrasound seems to detect more lesion than the radiography; with 21 times more erosions objectified for MCP and 30 times more for PPIs.

\subsubsection{Factors Associated with Ultrasound Lesions}

After multivariate analysis, Table 8 and Table 9 present the factors associated with bone erosions and active synovitis.

Table 6. Clinical and ultrasound concordance of active synovitis in patients followed for RA, Rheumatology department of the CNHU-HKM in $2018(\mathrm{~N}=53)$.

\begin{tabular}{cccccccc}
\hline & \multicolumn{9}{c}{ Ultrasound } & Total & Kappa (k) & Interpretation \\
\cline { 2 - 5 } & \multicolumn{2}{c}{ SA (+) } & \multicolumn{2}{c}{ SA (-) } & & \\
\hline Clinical & & & $(3.8)$ & 9 & $(17.0)$ & $11(20.8)$ & \\
\hline SA (+) & 2 & $(13.2)$ & 35 & $(66.0)$ & $42(79.2)$ & 0.16 & Very weak agreement \\
SA (-) & 7 & $(17.0)$ & 44 & $(83.0)$ & $53(100.0)$ & & \\
Total & 9 & $(10)$ & & & &
\end{tabular}

SA: Active Synovitis.

Table 7. Concomitant search for bone erosions according to the different groups of joints by ultrasound and radiography in patients followed for RA, Department of Rheumatology of the CNHU-HKM in $2018(\mathrm{~N}=53)$.

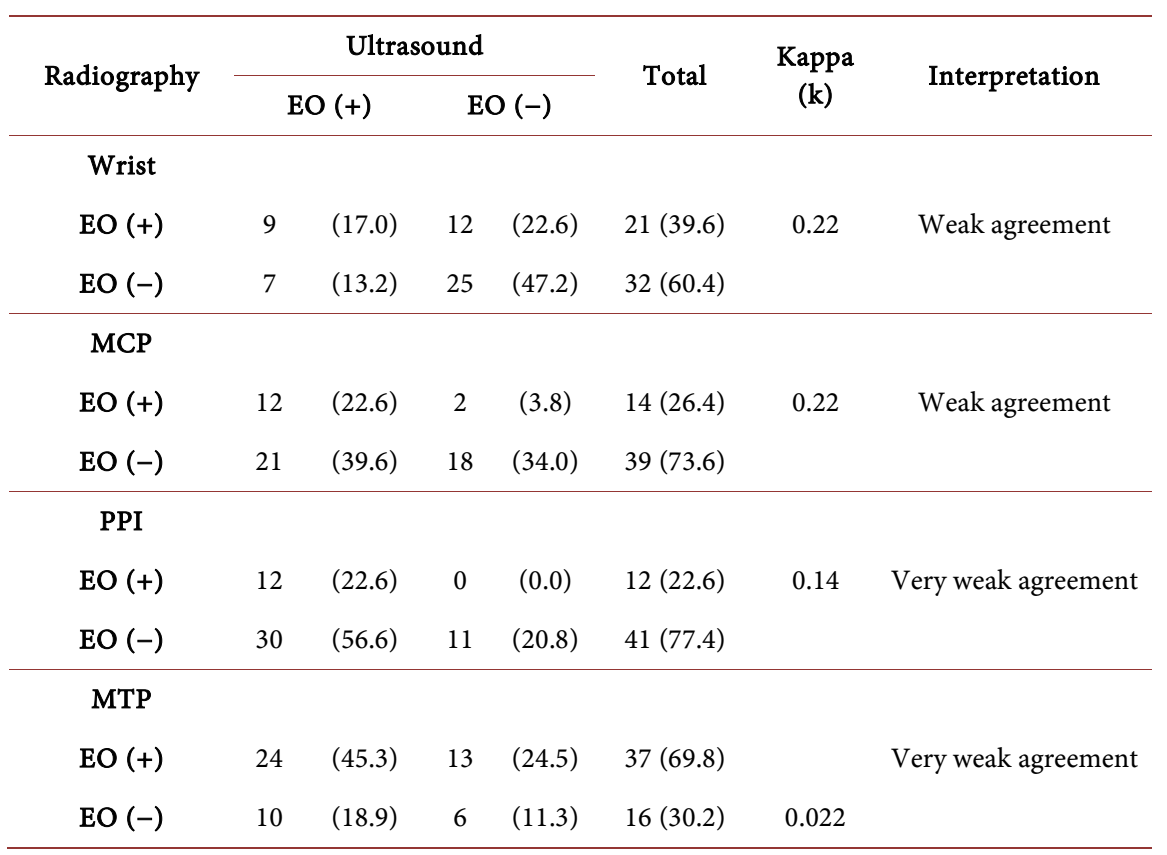


Table 8. Association between bone erosions and clinical and biological data.

\begin{tabular}{|c|c|c|c|c|c|}
\hline & \multirow{2}{*}{ Total (N) } & \multicolumn{3}{|c|}{ Bone erosions } & \multirow{2}{*}{$\mathrm{p}$} \\
\hline & & \multicolumn{2}{|c|}{ Yes } & No & \\
\hline \multicolumn{6}{|l|}{ Age (year) } \\
\hline$\leq 40$ & 9 & 4 & $(44.4)$ & 5 & \multirow{2}{*}{0.035} \\
\hline$>40$ & 44 & 5 & $(11.4)$ & 39 & \\
\hline \multicolumn{6}{|c|}{ AC Anti CCP } \\
\hline Positive & 15 & 13 & $(86.7)$ & 2 & \multirow{2}{*}{0.0001} \\
\hline Negative & 38 & 4 & $(89.5)$ & 34 & \\
\hline \multicolumn{6}{|c|}{ Inflammatory syndrome } \\
\hline Yes & 37 & 32 & $(86.5)$ & 5 & \multirow{2}{*}{0.0001} \\
\hline No & 16 & 1 & $(93.8)$ & 15 & \\
\hline
\end{tabular}

Table 9. Association between age and active synovitis.

\begin{tabular}{ccccccc}
\hline & & \multicolumn{3}{c}{ Active synovitis } & \\
\cline { 3 - 5 } & & & \multicolumn{2}{c}{ Yes } & No & \\
\hline Age (year) & 9 & 6 & $(66.7)$ & 3 & 0.022 \\
$\leq 40$ & 44 & 41 & $(93.2)$ & 3 & \\
\hline$>40$ & & & & & \\
\hline
\end{tabular}

\section{Discussion}

This preliminary work experienced one main difficulty during its completion, namely the presence of joint deformities in the patients, which made ultrasound examination difficult and sometimes impossible. The limits of this work also lie in the small number of our only female sample, the absence of control cases and the non-updating of certain biological assessments at the time of the study. Furthermore, the study did not isolate patients who were naïve to disease-modifying treatment for RA, from patients already on treatment because of the reduced number of the cohort. This should not impact on the internal and external validity of this work, the results of which have given rise to the following discussion.

Ultrasound lesions were present in all of our patients. This high frequency of RA-related ultrasound lesions is explained by the long time from beginning to diagnosis and also by the recognized performance of ultrasound which detects lesions even in the absence of clinical signs [10] [11]. Ultrasound synovitis was the most observed lesion (98.1\%). Naredo in 2013 and Vreju in 2016 [12] [13] found respectively $87.8 \%$ and $94.8 \%$ of ultrasound synovitis, unlike Harman $\mathrm{H}$. et al. who found 3 times fewer cases of ultrasound synovitis (36\%) [14]. This difference is explained by the fact that the cohort of Harman consisted mainly of patients in clinical remission for at least 6 months, whereas our study and others contained very few patients in complete remission. In addition, the too long diagnostic delay in our work and in Zomalheto et al.'s in patients with RA (>1 
year) could also explain this high proportion of ultrasound synovitis [4]. Doppler activity was found in $17 \%$ of our patients compared to $29 \%$ in Harman et al. [14] despite the fact that the entire population is in complete remission. Synovial inflammation may therefore persist in RA patients who experience clinical remission [10]. Several authors had also found active synovitis in patients suffering from RA in remission (DAS $\leq 2.6$ ) with frequencies of $36 \%, 46 \%$ and $57.4 \%$ [12] [15]. All this proves the performance of ultrasound in detecting subclinical synovitis in patients with RA in clinical remission. This subclinical synovitis could be linked to neoangiogenesis which persists for many months and which has been explored in numerous works such as those of Kamishima et al. [16].

We found bone erosions in 47 patients (88.7\%). Naredo in Spain, Vreju in Romania and Tanaka in France recorded 59\%, 21.7\% and 36.8\% bone erosion, respectively [12] [13] [17]. The long diagnostic delay in the patients in the present study would explain the high frequency of erosions on ultrasound. Apart from synovitis and bone erosions mainly present and studied in RA, our patients presented numerous other ultrasound lesions. These were joint effusion in 34\% of patients, tenosynovitis (20.8\%), de Quervain tendinitis (7.5\%) and overlapping and angulation-type deformities (60.4\% and 7.5\%). Tenosynovitis has also been described in studies as an ultrasound sign of RA in rheumatoid arthritis. In fact, apart from the articular tropism, the periarticular structures constitute a bed for rheumatoid disease [7] [18].

There was no match between clinical examination and ultrasound, for wrists, MCPs and MTPs. On the other hand, the concordance was very low at the level of the PPIs $(\mathrm{k}=0.03)$. Garrigues et al. found a very low concordance for MTPs $(\mathrm{k}=0.01-0.03)$ and wrists $(0.23$ to 0.30$)$ and moderate concordance for MCP (k $=0.47-0.51$ ), and PPIs (0.55) [19]. Garrigues et al. suggest that ultrasound assessment of RA patients might focus only on PTMs and wrists but also on shoulders and that other joint sites should be assessed by physical examination.

There was poor concordance between ultrasound and radiographic erosions at wrists, MCP, PPI, and MTP ( $\mathrm{k}$ between 0.022 and 0.22). Backhaus and Naredo found in their study, a similar concordance at the level of the distal joints [12] [20]. The use of small compact golf club type probes would facilitate exploration of the metacarpophalangeal joints, compared to linear probes. According to some authors, detecting bone erosions on ultrasound is especially useful in the first few months of the disease [21]. After one year of development, X-rays are just as effective, except for new erosions which will be detected earlier on MRI [21]. X-rays should be used as the initial imaging technique to detect joint damage. Ultrasound or MRI may be considered when X-rays do not show a lesion [21]. Ultrasound may be a valid and reproducible technique for detecting synovitis in the joints of the wrist and fingers. It may be considered for routine use as part of standard diagnostic tools in RA [7] [21] especially in developing countries like ours.

Age, positive RA factor, and biologic inflammatory syndrome were all significantly associated with ultrasound erosions. Comparable results have been re- 
ported in the literature in rheumatoid patients in clinical remission [22] [23]. As for active synovitis, only age was significantly associated. Vreju et al. found a significant association of active ultrasound synovitis with strong anti CCP antibody positivity, disease activity, as well as a significant correlation with serum levels of vascular endothelial growth factor (VEGF) and active synovitis on ultrasound [13].

Ultrasound abnormalities such as synovitis and bone erosions, however, are not specific to RA and can be seen in other chronic inflammatory rheumatism. The clinical context, the topography of the lesions as well as the biological assessment remain the best means of differentiating an incipient rheumatoid arthritis from other chronic inflammatory rheumatism.

\section{Conclusions}

Rheumatoid arthritis was found to be more common in Beninese women and affected the middle-aged population. Radiologically, RA was very destructive in our population. Synovitis and bone erosion are the most frequent Ultrasound manifestations. The main factor associated with these ultrasound lesions was age.

There is no concordance between ultrasound and clinical examination for wrists, PCMs and MTPs, but it was very weak for PPIs. There is a weak concordance between ultrasound erosions and radiographic erosions. The ultrasound seems, however, to detect more lesions than the radiography with 10 times and 30 times more erosions objectified respectively for MCP and PPI.

Ultrasound is by far a good complementary alternative to clinical examination and diagnostic radiography in the early diagnosis of RA in the absence of MRI, which remains a luxury in our developing countries.

\section{Acknowledgements}

The authors acknowledge all the patients followed for rheumatoid arthritis who agreed to collaborate in this study.

\section{Conflicts of Interest}

The authors declare no conflicts of interest regarding the publication of this paper.

\section{References}

[1] Scott, D., Wolfe, F. and Huizinga, T. (2010) Rheumatoid Arthritis. Lancet, 376, 1094-1108. https://doi.org/10.1016/S0140-6736(10)60826-4

[2] Van der Woude, D. and van der Helm-van Mil, A.H.M. (2018) Update on the Epidemiology, Risk Factors, and Disease Outcomes of Rheumatoid Arthritis. Best Practice \& Research Clinical Rheumatology, 32, 174-187. https://doi.org/10.1016/j.berh.2018.10.005

[3] Avimadjè, M., Gounongbé, M. and Zomalhetho, Z. (2009) La polyarthrite rhumatoide au centre national hospitalo-universitaire de Cotonou. Benin Méd, 57, 55-57. 
[4] Zomalhèto, Z., Biaou, O., Yèkpè-Ahouansou, P., Gounongbé, M. and Avimadjè, M. (2015) Polyarthrite rhumatoïde en milieu hospitalier à Cotonou. Journal Africain d'Imagerie Médicale, 7, 39-46.

[5] Pham, T. (2010) Comment intégrer l'imagerie moderne dans le diagnostic précoce et le suivi de la polyarthrite rhumatoïde ? Journal de Radiologie, 91, 120-125. https://doi.org/10.1016/S0221-0363(10)70017-2

[6] Østergaard, M. and Wiell, C. (2004) Ultrasonography in Rheumatoid Arthritis: A Very Promising Method Still Needing More Validation. Current Opinion in Rheumatology, 16, 223-230. https://doi.org/10.1097/00002281-200405000-00010

[7] Guerini, H., Ayral, X., Campagna, R., Feydy, A., Pluot, E., Rousseau, J., et al. (2010) Comment je fais un bilan échographique des mains et des pieds dans la polyarthrite rhumatoïde? Journal de Radiologie, 91, 99-110. https://doi.org/10.1016/S0221-0363(10)70015-9

[8] Bouty, N., Lardé, A., Demondion, X., Flipo, R.M. and Cotten, A. (2003) Polyarthrite rhumatoide débutante: Apport de l'échographie des articulations métacarpophalangiennes. Journal de radiologie, 84, 659-665.

[9] Landis, J.R. and Koch, G.G. (1977) The Measurement of Observer Agreement for Categorical Data. Biometrics, 33, 159-174. https://doi.org/10.2307/2529310

[10] do Prado, A.D., Staub, H.L., Bisi, M.C., da Silveira, I.G., Mendonça, J.A., Polido-Pereira, J., et al. (2018) Ultrasound and Its Clinical Use in Rheumatoid Arthritis: Where Do We Stand? Advances in Rheumatology, 58, Article No. 19.

https://doi.org/10.1186/s42358-018-0023-y

[11] Naredo, E., Collado, P., Cruz, A., Palop, M.J., Cabero, F., Richi, P., et al. (2007) Longitudinal Power Doppler Ultrasonographic Assessment of Joint Inflammatory Activity in Early Rheumatoid Arthritis: Predictive Value in Disease Activity and Radiologic Progression. Arthritis Care \& Research, 57, 116-124. https://doi.org/10.1002/art.22461

[12] Naredo, E., Valor, L., De la Torre, I., Martínez-Barrio, J., Hinojosa, M., Aramburu, F., et al. (2013) Ultrasound Joint Inflammation in Rheumatoid Arthritis in Clinical Remission: How Many and Which Joints Should Be Assessed? Arthritis Care \& Research, 65, 512-517. https://doi.org/10.1002/acr.21869

[13] Vreju, A.F., Chisalau, B.A., Parvanescu, C.D., Barbulescu, A., Rogoveanu, O., Firulescu, S., et al. (2016) High Frequency Ultrasonography of the Hand in Rheumatoid Arthritis, Psoriatic Arthritis, Gout and Osteoarthritis Patients. Current Health Sciences Journal, 42, 35-39. https://doi.org/10.12865/chsj.42.01.05

[14] Harman, H., Tekeoğlu, I., Kaban, N. and Harman, S. (2015) Factors Influencing Ultrasonographic Remission in Patients with Rheumatoid Arthritis. Rheumatology International, 35, 485-491. https://doi.org/10.1007/s00296-014-3177-X

[15] Peluso, G., Michelutti, A., Bosello, S., Gremese, E., Tolusso, B. and Ferraccioli, G. (2011) Clinical and Ultrasonographic Remission Determines Different Chances of Relapse in Early and Long Standing Rheumatoid Arthritis. Annals of the Rheumatic Diseases, 70, 172-175. https://doi.org/10.1136/ard.2010.129924

[16] Kamishima, T., Tanimura, K., Henmi, M., Narita, A., Sakamoto, F., Terae, S., et al. (2009) Power Doppler Ultrasound of Rheumatoid Synovitis: Quantification of Vascular Signal and Analysis of Interobserver Variability. Skeletal Radiology, 38, 467-472. https://doi.org/10.1007/s00256-009-0665-2

[17] Tanaka, Y. (2016) Current Concepts in the Management of Rheumatoid Arthritis. The Korean Journal of Internal Medicine, 31, 210-218.

https://doi.org/10.3904/kjim.2015.137 
[18] Ben Abdelghani, K., Miladi, S., Souabni, L., Kassab, S., Chekili, S., Laatar, A., et al. (2015) Apport de l'échographie ostéoarticulaire au cours de la polyarthrite rhumatoïde en rémission. Journal de Radiologie Diagnostique et Interventionnelle, 96, S1-S10. https://doi.org/10.1016/j.jradio.2014.05.012

[19] Garrigues, F., Jousse-Joulin, S., Bouttier, R., Nonent, M., Bressollette, L. and Saraux, A. (2013) Concordance clinique et échographique dans la polyarthrite rhumatoïde. Revue du Rhumatisme, 80, 569-576. https://doi.org/10.1016/j.rhum.2013.05.005

[20] Backhaus, M., Ohrndorf, S., Kellner, H., Strunk, J., Backhaus, T.M., Hartung, W., et al. (2009) Evaluation of a Novel 7-Joint Ultrasound Score in Daily Rheumatologic Practice: A Pilot Project. Arthritis Care \& Research, 61, 1194-1201. https://doi.org/10.1002/art.24646

[21] Zufferey, P. and Becce, F. (2014) Rôle de l'imagerie dans le diagnostic et le suivi de la polyarthrite rhumatoïde. Revue Médicale Suisse, 421, 585-589.

[22] Macchioni, P., Magnani, M., Mulè, R., Galletti, S., Catanoso, M., Pignotti, E., et al. (2013) Ultrasonographic Predictors for the Development of Joint Damage in Rheumatoid Arthritis Patients: A Single Joint Prospective Study. Clinical and Experimental Rheumatology, 31, 8-17.

[23] Newman, J.S., Adler, R.S., Bude, R.O. and Rubin, J.M. (1994) Detection of Soft-Tissue Hyperemia: Value of Power Doppler Sonography. American Journal of Roentgenology, 163, 385-389. https://doi.org/10.2214/ajr.163.2.8037037 